\title{
Reduced chemotherapeutic sensitivity in high glucose condition: implication of antioxidant response
}

\author{
Alessia Garufi $i^{1,2, *}$, Gianandrea Traversi ${ }^{1,2, *}$, Maria Saveria Gilardini Montani ${ }^{3}$, \\ Valerio D'Orazi ${ }^{4}$, Giuseppa Pistritto ${ }^{5}$, Mara Cirone ${ }^{3}$ and Gabriella D'Orazi ${ }^{1,2}$ \\ ${ }^{1}$ IRCCS Regina Elena National Cancer Institute, Department of Research, Rome 00144, Italy \\ ${ }^{2}$ University 'G. d'Annunzio', Department of Medical and Biotechnological Sciences, Chieti 66013, Italy \\ ${ }^{3}$ Sapienza University, Department of Experimental Medicine, Rome 00161, Italy \\ ${ }^{4}$ Department of Surgical Sciences, Rome 00161, Italy \\ ${ }^{5}$ University Tor Vergata, Department of Systems Medicine, Rome 00133, Italy \\ *These authors contributed equally to this work \\ Correspondence to: Gabriella D'Orazi, email: gdorazi@unich.it \\ Keywords: chemoresistance; reactive oxygen species (ROS); high glucose (HG); cancer; nuclear factor erythroid 2-related factor 2 (NRF2) \\ Received: April 23, 2019 \\ Accepted: July 05, 2019 \\ Published: July 23, 2019
}

Copyright: Garufi et al. This is an open-access article distributed under the terms of the Creative Commons Attribution License 3.0 (CC BY 3.0), which permits unrestricted use, distribution, and reproduction in any medium, provided the original author and source are credited.

\section{ABSTRACT}

Resistance to chemotherapy represents a major obstacle to successful treatment. The generation of reactive oxygen species (ROS) has been directly linked to the cytotoxic effects of several antitumor agents, including Adriamycin (ADR), and modulation of the oxidative balance has been implicated in the development and/or regulation of resistance to chemotherapeutic drugs. We recently showed that high glucose (HG) markedly diminished the cancer cell death induced by anticancer agents such as ADR. In the present study we attempted to evaluate the mechanism that impaired the cytotoxic effect of ADR in HG. We found that, in colon cancer cells, HG attenuated ADR-induced ROS production that consequently diminished ADRinduced H2AX phosphorylation and micronuclei (MN) formation. Mechanistically, HG attenuation of ADR-induced ROS production correlated with increased antioxidant response promoted by NRF 2 activity. Thus, pharmacologic inhibition of NRF2 pathway by brusatol re-established the ADR cytotoxic effect impaired by HG. Together, the data provide new insights into chemotherapeutic-resistance mechanisms in HG condition dictated by increased NRF2-induced antioxidant response and how they may be overcome in order to restore chemosensitivity and ADR-induced cell death.

\section{INTRODUCTION}

Chemotherapy can kill the drug-sensitive cancer cells, but the drug-resistant cells left behind can cause tumor recurrence (or relapse) and even cancer metastasis [1]. Development of drug resistance is therefore an important factor in anticancer therapeutic failure [2]. Two types of resistance occur, that is, intrinsic or acquired. Mechanistically, a variety of different systems contribute to chemoresistance including tumor heterogeneity, druginactivation, evasion of apoptosis, enhanced DNA repair and increased drug efflux [3-5]. The effectiveness of traditional cancer chemotherapy is largely based on the generation of reactive oxygen species (ROS) and consequently on the oxidative stress that exceeds the reduction capacity of cancer cells, leading ultimately to apoptosis or necrosis [6-8]. Most conventional and also non conventional chemotherapeutic agents as well as radiotherapeutic agents kill cancer cells by stimulating ROS generation [9-12]. Redox resetting usually occurs in anticancer drug treatment as a protective response from tumor cells to cope with drug-induced stress and DNA damage, leading ultimately to drug resistance [13]. Thus, alteration in redox balance, and deregulated redox signaling are common hallmarks of cancer progression and resistance to treatment [14]. ROS balance is typically regulated by antioxidant enzymes including catalase, superoxide dismutase (SOD) and glutathione S-transferase 
(GST) which detoxify ROS, reduce ROS-dependent apoptosis and attenuate chemotherapeutic cytotoxicity $[8,10]$. Antioxidant protein expression is regulated by the transcription factor nuclear factor erythroid 2-related factor 2 (NRF2) which is the major regulator of the antioxidant response [15]. NRF2 is activated during oxidative and electrophilic stress through release from its inhibitory Keap1 (Kelch-like ECH-associated protein 1) to bind antioxidant responsive elements (ARE) in the promoter of target genes including catalase, GST, SOD, and NAD(P)H quinone oxidoreductase 1 (NQO1) [16], promoting their transcription. However, noncanonical activation of NRF2 may also occur and is mediated by p62-induced KEAP1 degradation through autophagy [17] or by the p53 target p21 which upregulates the NRF2 signaling pathway by interrupting KEAP1/NRF2 interaction and therefore inducing NRF2 stabilization [18]. Activation of the NRF2-induced pathway in cancer has been shown to be critical for chemotherapeutic resistance. Among the NRF2 targets, catalase overexpression has been shown to protect cancer cells from apoptosis induced by DNA-damaging agents $[19,20]$. Similarly, a role of NQO1 in chemotherapeutic resistance has been demonstrated and inhibition of NQO1 has been shown to suppress cancer cell growth and to potentiate cytotoxicity of anticancer agents [21-23]. Therefore, targeting NRF2 signaling may be a potentially attractive target to combat chemoresistance [15, 16, 24]. Among NRF2-targeting agents brusatol, a quassinoid extracted from Brucea javanica, that has been shown to enhance the efficacy of chemotherapy by inhibiting the NRF2-mediated defense mechanism [25, 26].

We have previously reported that attenuation of drug-induced cancer cell death occurs when cancer cells are switched form low to high glucose $(\mathrm{HG})$ condition and are treated with Adiamycin, (ADR), highlighting by several mechanisms [27-30]. Since the production of ROS induced by the chemotherapeutic drug ADR is considered a major trigger for apoptotic cell death [31], in the present study we aimed at evaluating whether the reduced chemotherapeutic sensitivity promoted by $\mathrm{HG}$ in colon cancer cells might depend on deregulated ADR-induced ROS generation. To this end we evaluated the production of ROS and of the antioxidant response induced by ADR under conditions of low and high glucose in colon cancer cell lines, in vitro, and how it can modify drug-induced cell death.

\section{RESULTS}

\section{High glucose (HG) attenuated the ADR-induced ROS generation}

The ROS levels were first assessed in RKO and HCT116 cells treated with ADR in low and HG condition, by DCF fluorescence. Results show that ROS levels markedly increased when the cells were treated with ADR in low glucose (Figure 1, compare lane 2 with lane 1) but not when they were treated with ADR in HG (Figure 1, compare lane 2 with lane 3 ). Attenuation of ADR-induced ROS in HG was comparable to that obtained by using the ROS scavenger NAC in low glucose (Figure 1, compare lane 2 with lane 3 and lane 2 with lane 4). Of note, HG per se did not modify intracellular ROS levels, indicating that it was instead triggering some mechanisms to reduce the effect of the drug. These data indicate that HG lowered the production of ROS induced by ADR to levels comparable to that obtained by NAC inhibition of ROS production by ADR in low glucose.

\section{High glucose (HG) reduced ADR-induced DNA damage and cell death}

Then, we evaluated whether the modulation of ROS had an effect on drug-induced DNA damage and consequently on cell death. To this aim, $\gamma \mathrm{H} 2 \mathrm{AX}$ levels and micronuclei $(\mathrm{MN})$ formation were evaluated. $\mathrm{H} 2 \mathrm{AX}$ phosphorylation in Ser139, generating $\gamma \mathrm{H} 2 \mathrm{AX}$, occurs in general in response to double-strand brakes (DSB) and is an early sign of replication stalling [32]. We found that ADR treatment in low glucose strongly induced $\gamma \mathrm{H} 2 \mathrm{AX}$ levels while ADR treatment in $\mathrm{HG}$ condition failed to do so (Figure 2A), suggesting reduction of DNA damage. $\mathrm{MN}$ are acentric chromosomal fragments or whole chromosomes lost during cell division as a result of DNA damage and are commonly detected in cells exhibiting intrinsic genomic instability or following exposure to genotoxic agents $[33,34]$. We found that the ADR-induced $\mathrm{MN}$ formation in low glucose (Figure 2B, compare lane 2 with lane 1) was significantly reduced in $\mathrm{HG}$ condition (Figure 2B, compare lane 2 with lane 3 ). To evaluate the role of ROS in MN formation, the ROS scavenger NAC was used. The results show that the ADR-induced MN formation in low glucose was greatly reduced by NAC treatment (Figure 2B, compare lane 2 with lane 4 ) to the levels obtained by ADR in HG (Figure 2B, compare lane 4 with lane 3), confirming the role of drug-induced ROS in DNA damage.

Since drug-induced ROS generation and DNA damage are the major trigger for cell death [9-11] the cell viability was evaluated by FACS analysis. As shown in Figure $2 \mathrm{C}$, ADR treatment markedly increased cell death in low glucose (Figure 2C, compare lane 2 with lane 1), but this effect was attenuated by $\mathrm{HG}$ (Figure 2C, compare lane 2 with lane 3 ). In addition, NAC reduced ADR-induced cell death in low glucose (Figure 2C, compare lane 4 with lane 2) to the levels obtained by ADR in HG (Figure 2C, compare lane 4 with lane 3 ), in agreement with the above role of drug-induced ROS in inducing DNA damage. Of note, $\mathrm{HG}$ alone did not change cell death (Figure 2C), as previously shown [27]. Together, these results indicate that $\mathrm{HG}$ reduced the ADR-induced cell death as a consequence of attenuation of ROS production. 


\section{High glucose (HG) increased antioxidant response during ADR treatment}

We next aimed at evaluating the mechanisms involved in ROS modulation by HG, keeping in mind that the antioxidant response contributes to chemotherapeuticresistance $[6,9,10,14]$. We found that the levels of catalase, a ROS scavenger enzyme [19] (Figure 3A) and of NQO1, another antioxidant protein (Figure 3B) markedly increased when cells were treated with ADR in $\mathrm{HG}$, but not when cells were treated in low glucose (Figure 3A and Figure 3B, compare lane 3 with lane 2). In addition, greater NRF2 accumulation was achieved in cells treated with $\mathrm{ADR}$ in $\mathrm{HG}$, compared to the treatment in low glucose (Figure 3C, compare lane 2 with lane 1). Since the modulation of NRF2 levels does not clearly indicate its function, the NRF2 transcriptional activity was assessed by the NRF2 ARE-Luc assay. As shown in Figure 3D, ARE-Luc activity was greatly increased by ADR in HG condition (Figure 3D, compare lane 3 with lane 2) but only slightly enhanced in low glucose condition (Figure 3D, compare lane 1 with lane 2). Next we aimed at evaluating the role of NRF2 in modulation of the antioxidant response, by its pharmacologic inhibition. Among the NRF2-targeting agents, brusatol, a quassinoid extracted from Brucea javanica, has been shown to inhibit the NRF2-mediated defense mechanism [25]. We found that the NQO1 levels (Figure 3B, compare lane 3 with lane 4 ) as well as the NRF2 levels (Figure 3C, compare lane 2 with lane 3) in ADR/HG were greatly reduced by brusatol. In agreement, brusatol markedly reduced ADR-induced NRF2 ARE-Luc activity in HG condition (Figure 3D, compare lane 3 with lane 4). These findings suggest that in $\mathrm{ADR} / \mathrm{HG}$ condition an increased antioxidant response occurred, mediated by NRF2 activity.

\section{Inhibition of the antioxidant response rescued ADR-induced DNA damage and cell death, attenuated by high glucose (HG)}

Having established that an increased antioxidant response occurred when cells were treated with ADR in $\mathrm{HG}$, we aimed at evaluating whether its targeting could rescue ADR-induced DNA damage and cell death,

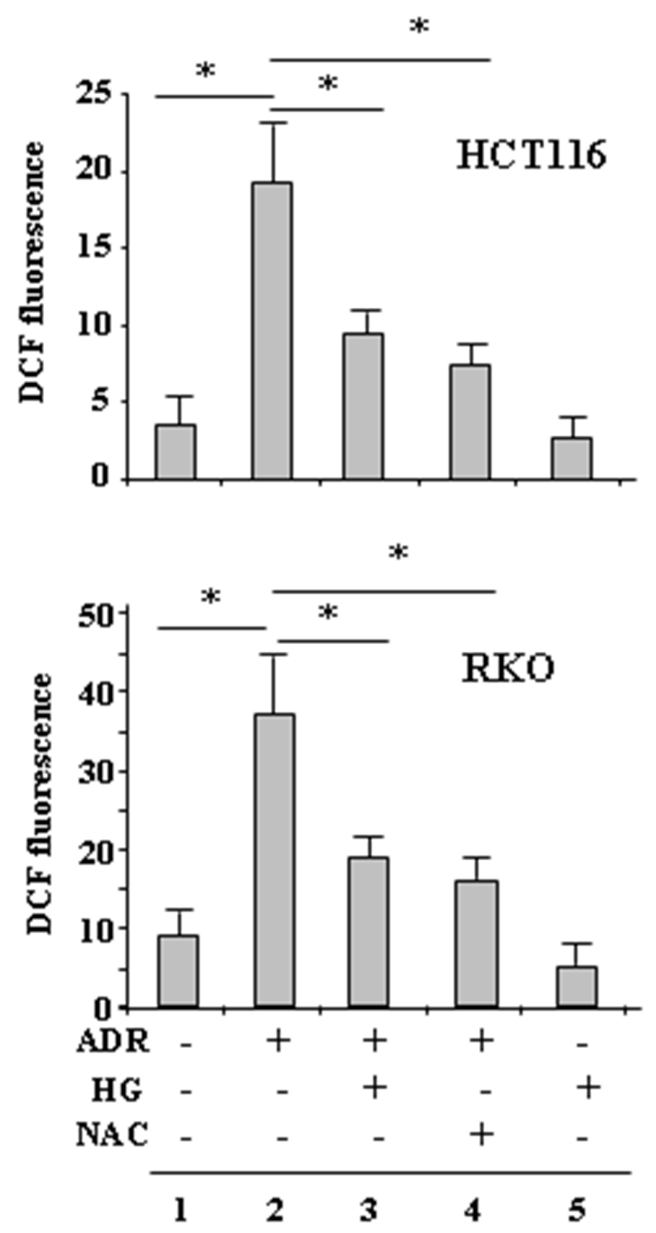

Figure 1: HG reduces ADR-induced ROS generation. HCT116 and RKO were treated with ADR (2 $\mu \mathrm{g} / \mathrm{ml}$ for $6 \mathrm{~h})$ in low or high glucose $(\mathrm{HG})$ with or without NAC $(10 \mu \mathrm{M}$, added $1 \mathrm{~h}$ before ADR). Then, the cells were incubated with $10 \mu \mathrm{M}$ DCFDA and fluorescence was determined by flow cytometry. Data shown are the means \pm s.d. of $n=3$ independent experiments; ANOVA test with Bonferroni correction: ${ }^{*} p<0.001$. 
A

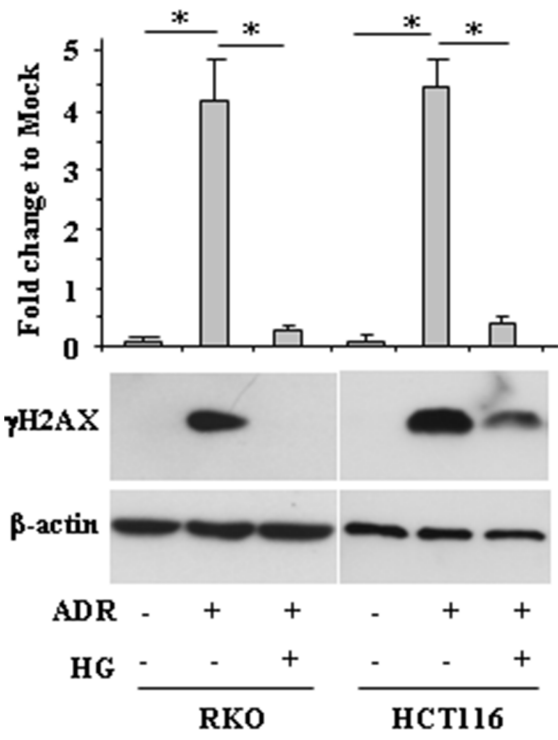

$\mathrm{C}$
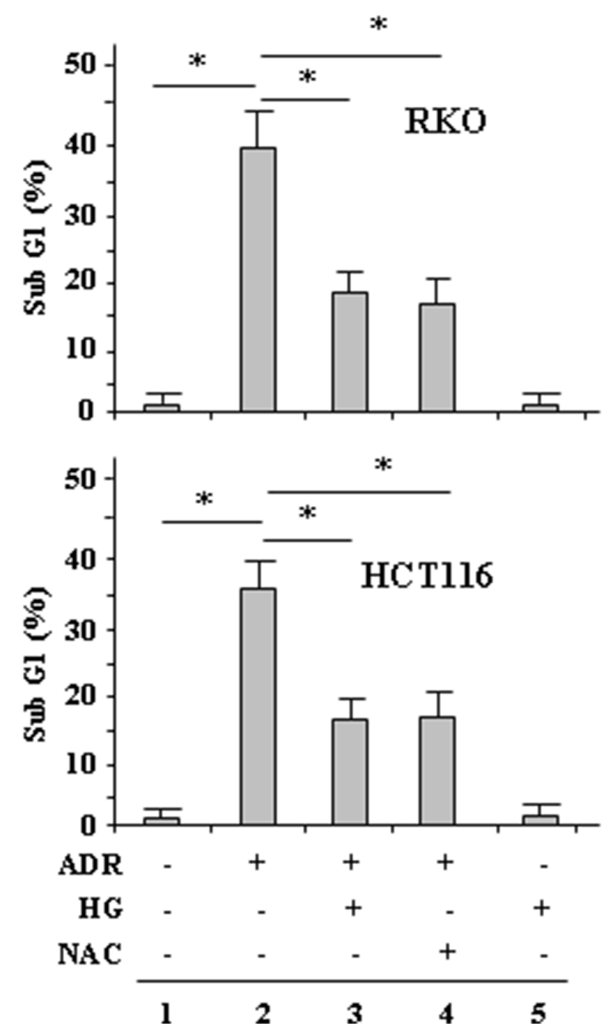

B
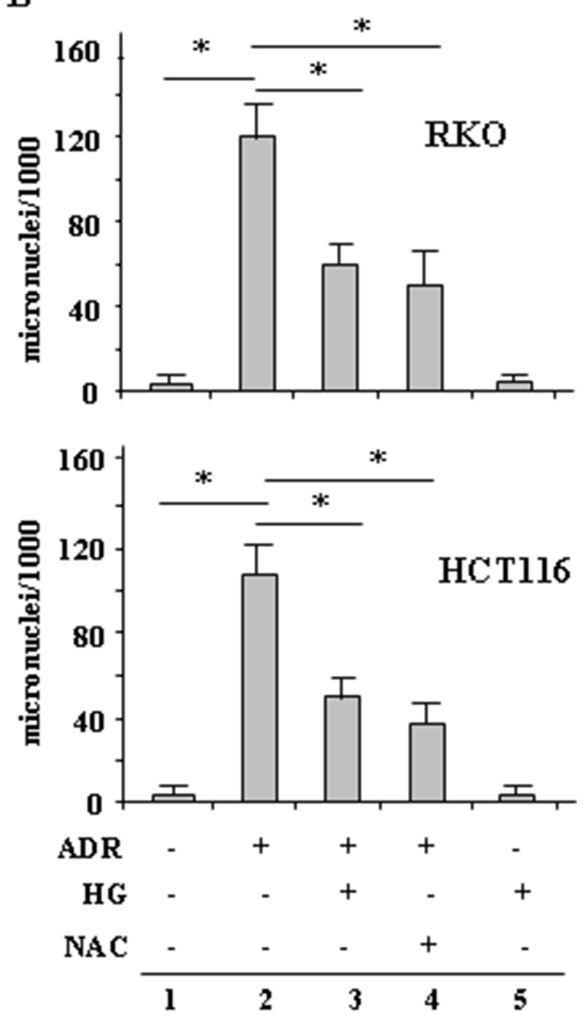

Figure 2: HG reduces ADR-induced DNA damage. (A), RKO and HCT116 were treated with ADR $(2 \mu \mathrm{g} / \mathrm{ml}$ for $16 \mathrm{~h})$ in low or high glucose (HG). Equal amount of total cell extracts was analysed by Western immunoblotting with anti- $\gamma \mathrm{H} 2 \mathrm{AX}$ antibody. Representative images are shown. Anti- $\beta$-actin was used as protein loading control. Densitometric analysis was applied to quantify $\gamma \mathrm{H} 2 \mathrm{AX}$ expression $/ \beta$ actin ratio and expressed as fold change to Mock (upper panel). Data are presented as the means \pm s.d. of $n=4$ independent experiments; ANOVA test with Bonferroni correction: ${ }^{*} p<0.001$. (B), RKO and HCT116 cells were treated with ADR $(2 \mu \mathrm{g} / \mathrm{ml})$ for $1 \mathrm{~h}$ with or without 1 $\mathrm{h}$ pretreatment with NAC $(10 \mu \mathrm{M})$, in low and HG. After treatments, fresh medium was added with $1 \mu \mathrm{g} / \mathrm{ml}$ cytochalasin B for $48 \mathrm{~h}$ in order to obtain binucleated $(\mathrm{BN})$ cells. Then, cells were stained with Giemsa and observed under a light microscope using high magnification $(\times 1000)$. The results are expressed as total MN on $1000 \mathrm{BN}$ cells $(\mathrm{MN} \%)$. Data are presented as the means \pm s.d. of $n=3$ independent experiments; ANOVA test with Bonferroni correction: " $p<0.001$. (C), RKO and HCT116 cells were treated with ADR (2 $\mu \mathrm{g} / \mathrm{ml})$ in low and HG with or without $1 \mathrm{~h}$ pretreatment with NAC $(10 \mu \mathrm{M})$. After $24 \mathrm{~h}$ treatment, cells were fixed and stained with PI for sub-G1 evaluation. Data are presented as the means \pm s.d. of $n=3$ independent experiments. ANOVA test with Bonferroni correction: ${ }^{*} p<0.001$. 
A

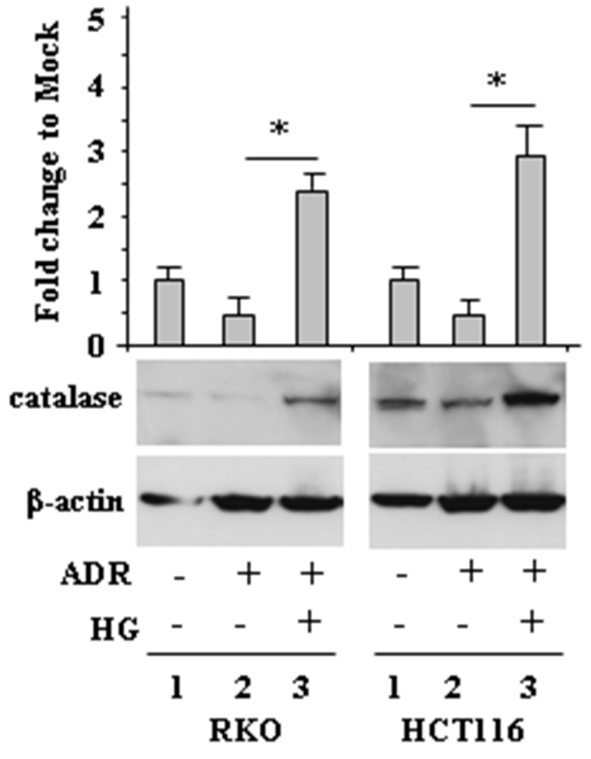

B

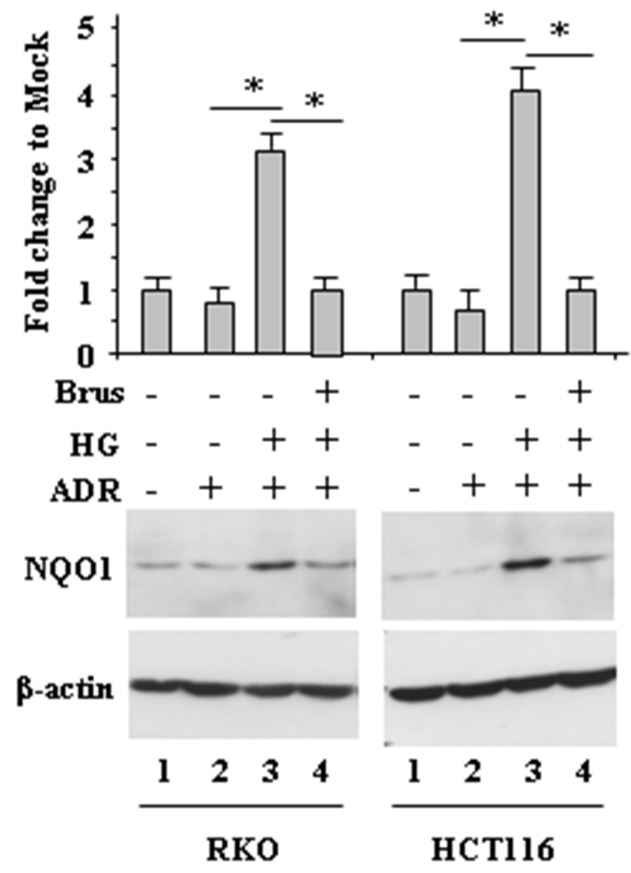

$\mathrm{C}$

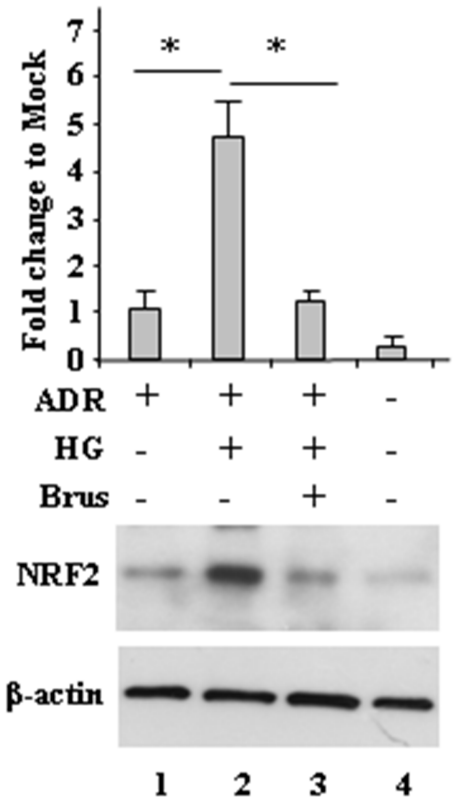

D

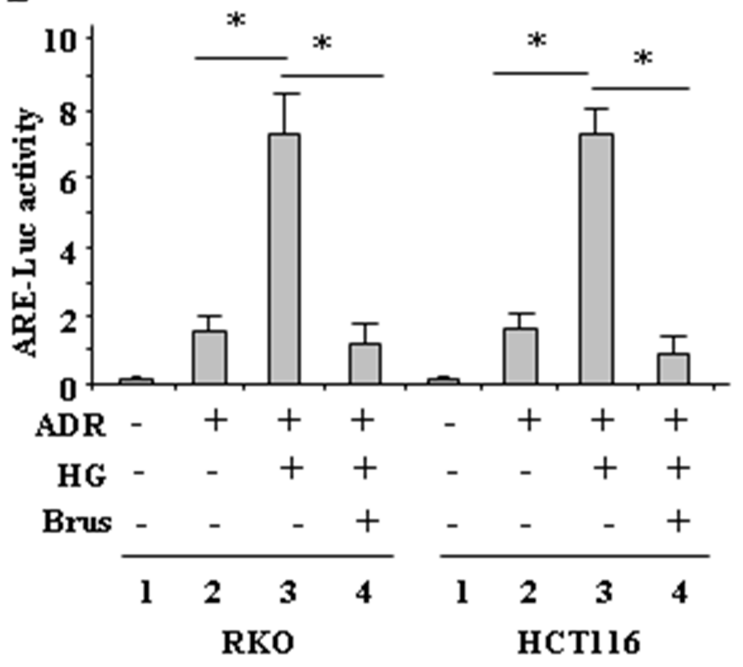

Figure 3: Increased antioxidant response during ADR treatment in HG condition. (A), RKO and HCT116 cells were treated with ADR $(2 \mu \mathrm{g} / \mathrm{ml}$ for $16 \mathrm{~h})$ in low glucose or HG. Equal amount of total cell extracts was analysed by Western immunoblotting with anticatalase antibody. Representative images are shown. Anti- $\beta$-actin was used as protein loading control. Densitometric analysis was applied to quantify catalase expression/ $\beta$-actin ratio and expressed as fold change to Mock, fixing the control to 1 . (B), RKO and HCT116 cells were pre-treated with brusatol $(100 \mathrm{nM}$ for $4 \mathrm{~h})$ and then treated with ADR $(2 \mu \mathrm{g} / \mathrm{ml}$ for $16 \mathrm{~h})$ in low glucose or HG. Equal amount of total cell extracts was analysed by Western immunoblotting with anti-NQO1 antibody. Representative images are shown. Anti- $\beta$-actin was used as protein loading control. Densitometric analysis was applied to quantify NQO1 expression/ $\beta$-actin ratio is expressed and expressed as fold change to Mock, fixing the control to 1. (C), RKO cells were pre-treated with brusatol (100 nM for $4 \mathrm{~h})$ and then treated with ADR (2 $\mu \mathrm{g} /$ $\mathrm{ml}$ for $16 \mathrm{~h}$ ) in low glucose or HG. Equal amount of total cell extracts was analysed by Western immunoblotting with anti-NRF2 antibody. Representative images are shown (upper panel). Anti- $\beta$-actin was used as protein loading control. Densitometric analysis was applied to quantify NRF2 expression/ $\beta$-actin ratio and expressed as fold change to Mock, fixing the control to 1 . (D), RKO and HCT116 cells were transfected with the NRF2 ARE-Luc vector and treated as in (C); then relative luciferase activity was measured. The results of ARE-luc activity are shown as the means \pm s.d. of $n=3$ independent experiments. ANOVA test with Bonferroni correction: ${ }^{*} p<0.001$. 
attenuated by $\mathrm{HG}$. We found that the lack of H2AX phosphorylation in $\mathrm{ADR} / \mathrm{HG}$ was counteracted by brusatol (Figure 4A, compare lane 3 with lane 4), taking back the $\gamma \mathrm{H} 2 \mathrm{AX}$ levels to those achieved by ADR in low glucose (Figure 4A, compare lane 4 with lane 2), suggesting reestablishment of ADR-induced DNA damage in HG. In agreement, cell viability analysis shows that the attenuation of ADR-induced cell death in $\mathrm{HG}$ (Figure 4B, compare lane 2 with lane 3 ), was counteracted by brusatol (Figure 4B, compare lane 3 with lane 4), taking back the cell death levels to those achieved by ADR in low glucose (Figure 4B, compare lane 4 with lane 2), suggesting re-establishment of ADR-induced cell death in HG. These data indicate that targeting the antioxidant response in $\mathrm{HG}$ could restore DNA damage and cell death in response to ADR.

\section{DISCUSSION}

A number of medical conditions can increase blood glucose concentration (hyperglycemia), including diabetes mellitus (DM), obesity, pancreatitis, chronic stress, and cancer $[35,36]$, and hyperglycemia has been shown to attenuate tumor therapeutic response and to confer resistance to chemotherapy-induced cell death [37, 38]. At molecular level, HG modulates various signaling pathways that control cancer cell proliferation, migration and recurrence [39, 40], as well as apoptosis [27, 39-43]. In our previous studies we showed that $\mathrm{HG}$ reduces ADRinduced cell death. Mechanistically, culturing cancer cells with $\mathrm{HG}$ or sera from diabetic patients reduces the drug-induced apoptotic activity of p53 [27, 28]. In this metabolic condition p53 changes its affinity for target promoters preferring for instance to transcribe damageregulated autophagy modulato (DRAM) that induces autophagy, instead of transcribing p53 upregulated modulator of apoptosis (PUMA), inducing a prosurvival autophagy whose inhibition can re-establish drug cytotoxicity [29]. The HG condition inhibits also the drug-induced c-jun-N-terminal kinase (JNK) pathway that can be rescued by $\mathrm{ZnCl}_{2}$ supplementation that counteracts the glycolytic pro-survival pathway restoring cancer cell chemosensitivity [30]. In vivo study confirmed that ADR treatment does not reduce the growth of a xenograft tumor in diabetic mice, as it does in normal glycemic control mice [29]. These findings are in agreement with preclinical studies where hyperglycemia is associated with attenuation of the antiproliferative effect of chemotherapy [44], underlining a multifaceted influence of hyperglycemia in the regulation of cancer cell chemosensitivity.

Most conventional and also non conventional chemotherapeutic agents as well as radiotherapeutic agents kill cancer cells by stimulating ROS generation that promotes DNA damage [6,9-12, 14]. In agreement, here we found that ADR-induced ROS increased DNA damage ultimately inducing cell death. However, when
ADR-induced ROS production was attenuated by $\mathrm{HG}$, also $\mathrm{H} 2 \mathrm{AX}$ phosphorylation and $\mathrm{MN}$ formation were reduced, along with cell death, linking the ROS production with DNA damage and cell death and therefore with the cell ability to cope with oxidative stress in order to survive. Therefore, we hypothesized a role for the antioxidant response to explain ROS modulation in $\mathrm{ADR} / \mathrm{HG}$ condition, corroborated by the fact that persistent oxidative stress induces adaptive responses including antioxidant up-regulation conferring resistance to apoptosis [7]. Thus, we found increased catalase and NQO1 levels in ADR/HG, suggesting indeed increased antioxidant response. Catalase overexpression has been shown to protect cancer cells from apoptosis induced by DNA-damaging agents, rendering catalase a future therapeutic target $[19,20]$. Similarly, a role of NQO1 in cancer chemotherapy has been demonstrated by several groups and inhibition of NQO1 has been shown to suppress cancer cell growth and to potentiate cytotoxicity of anticancer agents [21-23] and its downregulation may restore cancer cell sensitivity to chemotherapeutic agents as an attractive strategy for treating cancers. Although the antioxidant response can be seen as an obstacle to the drug cytotoxic effect, one limitation of our study is that we used only one drug to show the antioxidant mechanism in $\mathrm{HG}$ condition. It would be interesting to test if also other drugs that stimulate ROS generation as a mechanism of cell death might undergo increased antioxidant response in HG. Therefore, more experiments with different drugs should be performed in order to generalize these findings and make them useful for clinical applications. Another point that needs to be further explored is if high glucose could interfere with uptake of ADR or be direct on adriamycin metabolism by impairing the effectiveness of the chemotherapy itself.

Antioxidant proteins expression is regulated by NRF2 whose activation provides a growth advantage for cancer cells, protects against oxidative stress, and contributes to chemotherapeutic-resistance $[45,46]$. Under unstressed condition, NRF2 forms a complex with Keap1, leading to protein degradation. Upon exposure to different stressors, including ROS, toxic agents and carcinogens, NRF2 is released from Keap1, translocates to the nucleus, binds AREs in antioxidant gene promoters and up-regulates expression of target genes [47]. However, noncanonical activation of NRF2 may exists mediated, for instance, by p53 target p 21 that, by interrupting KEAP1/ NRF2 interaction, induces NRF2 accumulation and upregulates the NRF2 signaling pathway [18]. Here, we found that ADR treatment in HG condition increased the NRF2 activity and the expression of NRF2 target genes catalase and NQO1, thus contributing to reduce the drug cytotoxic effect. In the attempt to explain the mechanisms of NRF2 up-regulation, we can argue that p53 may play a role. Thus, we have previously reported that $\mathrm{HG}$, by modulating p53 post-translational modifications and 
therefore p53 transactivation function, reduces the p53induced apoptotic gene transcription while increases the transcription of autophagy gene such as DRAM or p21 (data not shown). It could be likely that $\mathrm{p} 21$, in this ADR/ HG setting, could activate NRF2, although further studies are needed to explain this link.

Having assessed that an increased antioxidant response occurred in $\mathrm{ADR} / \mathrm{HG}$, we aimed at evaluating whether its manipulation could rescue ADR-induced DNA damage and cell death, attenuated by HG. NRF2targeting agents can be used to overcome antioxidant response-dependent chemotherapeutic-resistance [24] and brusatol, a quassinoid extracted from Brucea javanica, has been shown to enhance the efficacy of chemotherapy by inhibiting the NRF2-mediated defense mechanism $[25,26]$. Brusatol may abrogate gemcitabine-induced NRF2 activation in pancreatic cancer cells to restore chemosensitivity of cancer cells [48]; may enhance the radiosensitivity of lung cancer cells by promoting ROS production and enhancing DNA damage [49]; and may

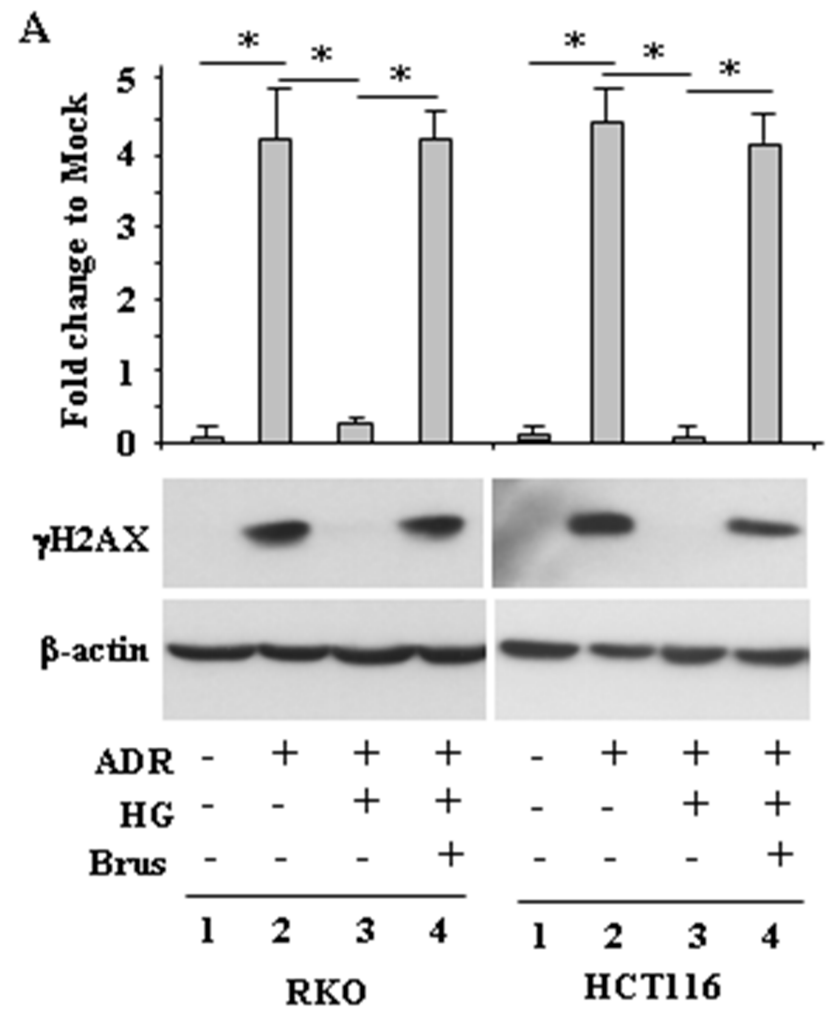

inhibit cancer cell growth and induce apoptosis via JNK/ p38 MAPK/NF-кb/Stat3/Bcl-2 [50]. In line with these findings, we show that brusatol re-sensitized cancer cells to drug cytotoxic activity inhibited by HG and inhibited NRF2-dependent activity.

In summary, the present study shows that $\mathrm{HG}$ reduced ADR-induced cell death by impairment of ROS production and increased antioxidant response through induction of the NRF2 activity. Therefore, this study may suggest that targeting the antioxidant response might contribute to restore chemotherapeutic sensitivity and ADR-induced cell death, inhibited by HG. In addition, once this mechanism is validated by using different anticancer agents, the concept to highlight the antioxidant response could be exploited also for predictive and prognostic purposes. To this aim, the new technological method of liquid biopsy could be of help in measuring for instance circulating tumor DNA and micro-RNA modified by $\mathrm{HG}$ and in response to drugs [51-53].
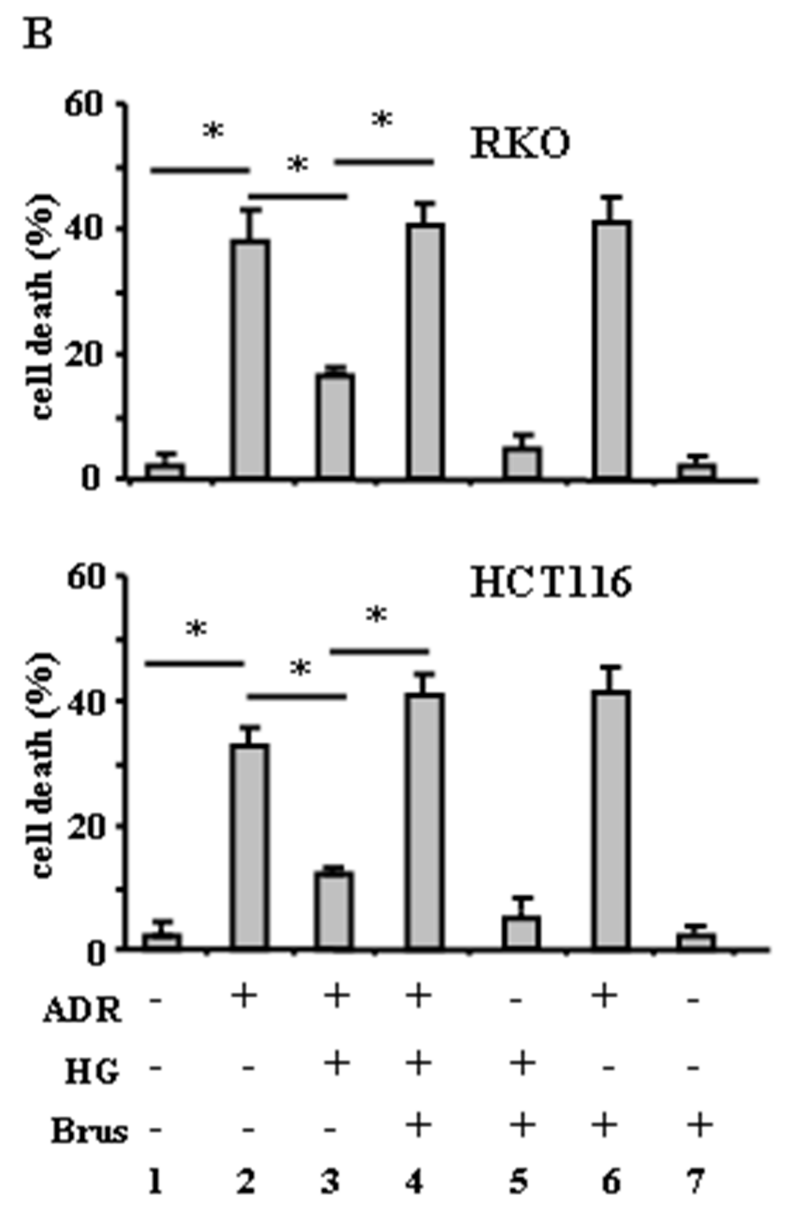

Figure 4: Brusatol restores ADR-induced DNA damage and cell death impaired by HG. (A), RKO and HCT116 cells were pre-treatred with brusatol (100 $\mathrm{nM}$ for $4 \mathrm{~h})$ prior to adding ADR $(2 \mu \mathrm{g} / \mathrm{ml}$ for $16 \mathrm{~h})$, in low glucose and in HG. Equal amount of total cell extracts was analysed by Western immunoblotting with anti- $\gamma \mathrm{H} 2 \mathrm{AX}$ antibody. Representative images are shown. Anti- $\beta$-actin was used as protein loading control. Densitometric analysis was applied to quantify NRF2 expression/ $\beta$-actin ratio. (B), RKO and HCT116 cells were treated as in (A) and $24 \mathrm{~h}$ after treatments, the percentage of dead cells was scored by Trypan blue staining. Data shown are the means $\pm \mathrm{s} . \mathrm{d}$. of $n=3$ independent experiments. ANOVA test with Bonferroni correction: ${ }^{*} p<0.001$. 


\section{MATERIALS AND METHODS}

\section{Cell culture and reagents}

Mycoplasma negative human RKO and HCT116 colon cancer cell lines (ATCC) were routinely cultured in Dulbecco modified Eagle's medium (DMEM) (Life Technology-Invitrogen, Carlsbad, CA, USA) containing $1 \mathrm{~g} / \mathrm{L}$ D-glucose (considered low glucose) supplemented with $10 \%$ heat-inactivated foetal bovine serum (FBS) (GIBCO-BRL, Grand Island, NY, USA) plus 100 units/ $\mathrm{ml}$ penicillin/streptomycin and glutamine in $5 \% \mathrm{CO}_{2}$ humidified incubator at $37^{\circ} \mathrm{C}$. For the experiments in high glucose (HG), cells, routinely cultured in medium containing $1 \mathrm{~g} / \mathrm{L}$ D-glucose, were washed in PBS, and then replaced with culture medium containing 4.5 $\mathrm{g} / \mathrm{L}$ D-glucose (high glucose - HG) plus 2\% FBS, as previously reported $[27,39,40]$. Control experiments in low glucose were also performed in $2 \%$ FBS.

The chemotherapeutic drugs Doxorubicin (herein referred as Adriamycin, ADR) (Sigma-Aldrich) was added to the culture media at $2 \mu \mathrm{g} / \mathrm{ml}$ for the indicated times. The ADR amount used in this study, that is $2 \mu \mathrm{g} / \mathrm{ml}$, was previously reported by us to induce apoptosis in RKO and HCT116 cells [27]. The ROS inhibitor N-acetyl-L-cysteine (NAC) (Sigma-Aldrich, St Louis. MO, USA) was used at $10 \mu \mathrm{M}$; antioxidant response inhibitor Brusatol (SigmaAldrich) was used at $100 \mathrm{nM}$; Cytochalasin B (Sigma, St Louis, MO, USA) was used at $1 \mu \mathrm{g} / \mathrm{ml}$.

\section{Measurement of intracellular reactive oxygen species (ROS) production}

To measure reactive oxygen species (ROS) production, we used 2',7'-dichlorofluorescein diacetate (DCFDA; Sigma-Aldrich), a highly fluorescent compound that after diffusion into the cell, is oxidized by ROS into $2^{\prime}, 7^{\prime}$-dichlorofluorescein (DCF), and can be detected by fluorescence spectroscopy, as reported [54]. Briefly, cells were plated in duplicate on six-well culture plates. The day after plating, cells were washed in PBS before adding HG culture media and low glucose media for the controls, for $24 \mathrm{~h}$ prior to adding the indicated treatments (ADR - 2 $\mu \mathrm{g} / \mathrm{ml}$ - for $6 \mathrm{~h}$ in the presence or absence of NAC - $10 \mu \mathrm{M}$ - added $1 \mathrm{~h}$ before ADR). Following treatment, cells were washed with PBS and incubated with $10 \mu \mathrm{M}$ DCFDA, for $15 \mathrm{~min}$ at $37^{\circ} \mathrm{C}$. Cell pellets were then collected and analyzed in the FL-1 channel of a FACScalibur flow cytometer (Becton-Dickinson). DCF fluorescence was determined using $5 \times 10^{5}$ cells $/ \mathrm{ml}$ and values expressed as mean DCF fluorescence per cell population.

\section{Cell viability}

To measure cell viability we used Trypan blues staining, as previously reported [27]. Briefly, equal numbers of cells were plated in duplicate in $60 \mathrm{~mm}$ Petri dishes. The day after plating, cells were washed in PBS before adding HG culture media and low glucose media for the controls, for $24 \mathrm{~h}$ before dispensing the indicated treatments. Cell viability was determined by Trypan blue staining of both floating and adherent cells and was measured by direct counting blue/white cells with a haemocytometer. The percentage of dead cell (blue/total) was calculated from 200 cells per well in triplicate.

\section{Cell death/PI staining}

Cell death was quantified by Fluorescence Activated Cell Sorting (FACS) analysis, staining cells with the nonvital dye propidium iodide (PI) (Immunological Sciences, Rome, Italy), following the manufacturer's instruction. Briefly, adherent cells were tripsinized and then collected along with floating cells by centrifugation; then, cell pellets were fixed in $80 \%$ ethanol and stained in a PBS solution containing propidium iodide (PI) $(62.5$ $\mathrm{mg} / \mathrm{ml}$; Sigma-Aldrich) and RNase A Q10 (1.125 mg/ ml; Sigma-Aldrich), as reported [55]. Stained samples were then analyzed with a FACScan instrument (Becton Dickinson Europe Holdings SAS - Le Pont De Claix, France) and the percentage of cells in sub G1 compartment was calculated using ModFit LT software (Becton Dickinson). Approximately 30000 events were acquired and gated using forward scatter and side scatter to exclude cell debris.

\section{Analysis of micronuclei (MN) by Cytokinesis- block micronucleus (CBMN) assay}

Analysis of MN was assessed by Cytokinesis-block micronucleus (CBMN) assay [56]. Briefly, $3 \times 10^{5}$ cells were seeded on coverslips in $60 \mathrm{~mm}$ Petri dish. The day after plating, cells were washed in PBS before adding HG culture media and low glucose media for the controls, for $24 \mathrm{~h}$ prior to adding a pulse of ADR $(2 \mu \mathrm{g} / \mathrm{ml})$ for $1 \mathrm{~h}$, with or without NAC $(10 \mu \mathrm{M}$, added $1 \mathrm{~h}$ before ADR). Following treatment, cells were replaced with fresh medium containing $1 \mu \mathrm{g} / \mathrm{ml}$ cytochalasin $\mathrm{B}$, for $48 \mathrm{~h}$, in order to obtain binucleated $(\mathrm{BN})$ cells. Cells were then fixed in cold methanol for $10 \mathrm{~min}$, air dried and stained with Giemsa. The coverslips were mounted on slides that were observed under a light microscope using high magnification $(\times 1000)$. For each experimental point, at least $1000 \mathrm{BN}$ cells were analysed, cells with one or more $\mathrm{MN}$ recorded and results expressed as total $\mathrm{MN}$ on 1000 BN cells (MN\%o).

\section{Western blot analysis}

Total cell extracts were prepared by incubation in lysis buffer ( $50 \mathrm{mM}$ Tris- $\mathrm{HCl}, \mathrm{pH} 7.5,150 \mathrm{mM} \mathrm{NaCl}, 5$ mM EDTA, pH 8.0, $150 \mathrm{mM} \mathrm{KCl,} 1 \mathrm{mM}$ dithiothreitol, 
$1 \%$ Nonidet P-40) and a mix of protease and phosphatase inhibitors (Roche, Indianapolis, IN, USA) on ice for 30 min. Cell debris was removed by centrifugation $(15000 \times \mathrm{g}$ for $20 \mathrm{~min}$ ) and supernatant collected. Protein concentration was determined using BCA Protein Assay kit (BioRad, Hercules, CA, USA). Samples were denatured in SDS sample buffer. Total cell extracts (10-40 $\mu \mathrm{g}$ total cell lysate/lane) were resolved by 9-18\% SDS polyacrylamide gel electrophoresis and transferred to polyvinylidene difluoride (PVDF) (Merck Millipore, Billerica, MA, USA) or nitrocellulose (BioRad) membranes by using the MiniPROTEAN 3 apparatus (Bio-Rad). Unspecific binding sites were blocked by incubating membranes for $1 \mathrm{~h}$ in $0.05 \%$ Tween-20 (v/v in TBS) supplemented with $5 \%$ non-fat powdered milk or bovine serum albumin (BSA) (SIGMA-Aldrich), followed by overnight $(\mathrm{o} / \mathrm{n})$ incubation with the following primary antibodies: mouse monoclonal anti-phospho-Histone H2AX (Ser139) (Millipore), rabbit monoclonal anti-NRF2 (Abcam, ab62352), mouse monoclonal anti-catalase (H-9) (Santa Cruz Biotechnology, sc-271803), mouse monoclonal antiNQO1 (A180) (Thermo-Scientific). Primary antibodies were detected with appropriate anti-immunoglobulin-Ghorseradish peroxidase secondary antibodies (BioRad). Enzymatic signals were visualized by chemiluminescence (ECL Detection system, Amersham GE Healthcare, Milan, Italy), according to the manufacturer's protocol. Equal lane loading was monitored by probing membranes with antibodies specific for mouse monoclonal $\beta$-actin (Calbiochem, San Diego, CA, USA). Densitometry was performed with ImageJ software and relative band intensity normalized to $\beta$-actin and quantified with respect to controls set to 1.0 .

\section{NRF2 ARE-Luc activity}

Sub-confluent cells were plated on white clear bottom 96-multiwell culture plates. The day after, cells were transfected with the NRF2 ARE-Luc reporter vector (ARE Reporter kit, antioxidant pathway, BPS Bioscience), using Lipofectamine Plus reagent according to the manufacturer's instructions (Invitrogen, Carlsbad, CA, USA). Sixteen hours after transfection, cells were washed in PBS before adding HG culture media, and low glucose media for the controls, pre-treated with brusatol $(100 \mathrm{nM}$ for $4 \mathrm{~h})$ followed by the addition of ADR $(2 \mu \mathrm{g} /$ $\mathrm{ml}$ for $16 \mathrm{~h}$ ). Luciferase activity was assayed on wholecell extracts, according to the manufacturer's instructions.

\section{Statistical analysis}

Each experiment, was performed at least three times. Results are reported as the mean \pm standard deviation (s.d.) or as fold change to mock or as protein expression/ $\beta$ actin ratio expressed as numbers underneath images fixing the control to 1. Statistical significance was determined using one-way ANOVA analysis for three or more sample comparisons using GraphPad Prism software (San Diego, CA, USA), with post hoc Bonferroni correction. A value of $p<0.05$ was considered statistically significant.

\section{Abbreviations}

ADR: adriamycin; ARE: antioxidant responsive elements; CBMN: cytokinesis-block micronucleus; DCF: dichlorofluorescein; DCFDA: dichlorofluorescein diacetate; DM: diabetes mellitus; DMEM: Dulbecco modified Eagle's medium; DSB: double-strand brakes; FBS: foetal bovine serum; GST: glutathione S-transferase; HG: high glucose; HO-1: heme oxygenase 1; JNK: c-JunN-terminal kinase; Keap1: Kelch-like ECHassociated protein 1; MN: micronuclei; NAC: N-acetylL-cysteine; NQO1: NAD(P)H:quinone oxidoreductase 1; NRF2: nuclear factor erythroid 2-related factor 2; PI: propidium iodide; PVDF: polyvinylidene difluoride; ROS: reactive oxygen species; SD: standard deviation; SOD: superoxide dismutase.

\section{Author contributions}

GD conceived and designed the experiments. AG, GT, MSGM, VD, and GP carried out the experiments. GD and MC analyzed the data. GD wrote the paper. All authors reviewed and approved the final manuscript.

\section{ACKNOWLEDGMENTS AND FUNDING}

We thank A. Verdina and S. Soddu for critical discussion and for sharing reagents; and A.R. Mackay for manuscript editing. The present study was supported by the Italian Association for Cancer Research (AIRC) Grant to GD (IG 2015 Id.16742).

\section{CONFLICTS OF INTEREST}

None.

\section{REFERENCES}

1. Mansoori B, Mohammadi A, Davudian S, Shirjang S, Baradaran B. The different mechanisms of cancer drug resistance: A brief review. Adv Pharm Bull. 2017; 7:339-48. https://doi.org/10.15171/apb.2017.041. [PubMed]

2. Housman G, Byler S, Heerboth S, Lapinska K, Longacre M, Snyder N, Sarkar S. Drug resistance in cancer: an overview. Cancers (Basel). 2014; 6:1769-92. https://doi.org/10.3390/ cancers6031769. [PubMed]

3. Zahreddine $\mathrm{H}$, Borden KL. Mechanisms and insights into drug resistance in cancer. Front Pharmacol. 2013; 4:28. https://doi.org/10.3389/fphar.2013.00028. [PubMed] 
4. Yin X, Tang B, Li JH, Wang Y, Zhang L, Xie XY, Zhang BH, Qiu SJ, Wu WZ, Ren ZG. ID1 promotes hepatocellular carcinoma proliferation and confers chemoresistance to oxaliplatin by activating pentose phosphate pathway. J Exp Clin Cancer Res. 2017; 36:166. https://doi.org/10.1186/ s13046-017-0637-7. [PubMed]

5. Zhang S, Yang Y, Weng W, Guo B, Cai G, Ma Y, Cai S. Fusobacterium nucleatum promotes chemoresistance to 5-fluorouracil by upregulation of BIRC3 expression in colorectal cancer. J Exp Clin Cancer Res. 2019; 38:14. https://doi.org/10.1186/s13046-018-0985-y. [PubMed]

6. Castaldo SA, Freitas JR, Conchinha NV, Madureira PA. The tumorigenic roles of the cellular REDOX regulatory systems. Oxida Med Cell Longev. 2016; 2016:8413032. https://doi.org/10.1155/2016/8413032. [PubMed]

7. Marengo B, Nitti M, Furfaro AL, Colla R, Ciucis CD, Marinari UM, Pronzato MA, Traverso N, Domenicotti C. Redox homeostasis and cellular antioxidant systems: crucial players in cancer growth and therapy. Oxid Med Cell Longev. 2016; 2016:6235641. https://doi. org/10.1155/2016/6235641. [PubMed]

8. Kumari S, Badana AK, Mohan MG, Shailender G, Malla RR. Reactive oxygen species: A key constituent in cancer survival. Biomark Insights. 2018; 13:1177271918755391. https://doi.org/10.1177/1177271918755391. [PubMed]

9. Ivanova D, Bakalova R, Lazarova D, Gadjeva V, Zhelev Z. The impact of reactive oxygen species on anticancer therapeutic strategies. Adv Clin Exp Med. 2013; 22:899908. [PubMed]

10. Chen J. Reactive oxygen species and drug resistance in cancer chemotherapy. Austin J Clin Pathol. 2014; 1:1-7.

11. Yang H, Villani RM, Wang H, Simpson MJ, Roberts MS, Tang $\mathrm{M}$, Liang X. The role of cellular reactive oxygen species in cancer chemotherapy. J Exp Clin Cancer Res. 2018; 37:266. https://doi.org/10.1186/s13046-018-0909-x. [PubMed]

12. Liu N, Wang KS, Qi M, Zhou YJ, Zeng GY, Tao J, Zhou JD, Zhang JL, Chen X, Peng C. Vitexin compound 1, a novel extraction from a Chinese herb, suppresses melanoma cell growth through DNA damage by increasing ROS levels. J Exp Clin Cancer Res. 2018; 37:269. https://doi.org/10.1186/ s13046-018-0897-x. [PubMed]

13. Liu Y, Li Q, Zhou L, Xie N, Nice EC, Zhang H, Huang C, Lei Y. Cancer drug resistance: redox resetting renders a way. Oncotarget. 2016; 7:42740-61. https://doi.org/10.18632/ oncotarget.8600. [PubMed]

14. Teppo HR, Soini Y, Karihtala P. Reactive oxygen speciesmediated mechanisms of action of targeted cancer therapy. Oxid Med Cell Longev. 2017; 2017:1485283. https://doi. org/10.1155/2017/1485283. [PubMed]

15. Ma Q. Role of nrf2 in oxidative stress and toxicity. Annu Rev Pharmacol Toxicol. 2013; 53:401-26. https://doi. org/10.1146/annurev-pharmtox-011112-140320. [PubMed]

16. Rojo de la Vega M, Chapman E, Zhang DD. NRF2 and the hallmarks of cancer. Cancer Cell. 2018; 34:21-43. https:// doi.org/10.1016/j.ccell.2018.03.022. [PubMed]
17. Jiang T, Harder B, Rojo de la Vega M, Wong PK, Chapman E, Zhang DD. p62 links autophagy and Nrf2 signaling. Free Radic Biol Med. 2015; 88:199-204. https://doi. org/10.1016/j.freeradbiomed.2015.06.014. [PubMed]

18. Chen W, Sun Z, Wang XJ, Jiang T, Huang Z, Fang D, Zhang DD. Direct interaction between Nrf2 and p21(Cip1/WAF1) upregulates the Nrf2-mediated antioxidant response. Mol Cell. 2009; 34:663-73. https://doi.org/10.1016/j. molcel.2009.04.029. [PubMed]

19. Glorieux C, Calderon PB. Catalase, a remarkable enzyme: targeting the oldest antioxidant enzyme to find a new cancer treatment approach. Biol Chem. 2017; 398:1095-108. https://doi.org/10.1515/hsz-2017-0131. [PubMed]

20. Glorieux C, Calderon PB. Catalase down-regulation in cancer cells exposed to arsenic trioxide is involved in their increased sensitivity to a pro-oxidant treatment. Cancer Cell Int. 2018; 18:24. https://doi.org/10.1186/s12935-018-0524-0. [PubMed]

21. Zeekpudsa P, Kukongviriyapan V, Senggunprai L, Sripa B, Prawan A. Suppression of NAD $(\mathrm{P}) \mathrm{H}$-quinone oxidoreductase 1 enhanced the susceptibility of cholangiocarcinoma cells to chemotherapeutic agents. J Exp Clin Cancer Res. 2014; 33:11. https://doi.org/10.1186/17569966-33-11. [PubMed]

22. Yang Y, Zhang Y, Wu Q, Cui X, Lin Z, Liu S, Chen L. Clinical implications of high NQO1 expression in breast cancers. J Exp Clin Cancer Res. 2014; 33:14. https://doi. org/10.1186/1756-9966-33-14. [ubMed]

23. Peng L, Duan Y, Zhang Y, Zhao D, Wen Y, Yao J, Da M. Expression of Nrf2 and NQO1 in human gastric cancer and their clinical significance. Int J Clin Exp Pathol. 2016; 9:1635-43.

24. No JH, Kim YB, Song YS. Targeting nrf2 signaling to combat chemoresistance. J Cancer Prev. 2014; 19:111-17. https://doi.org/10.15430/JCP.2014.19.2.111. [PubMed]

25. Ren D, Villeneuve NF, Jiang T, Wu T, Lau A, Toppin HA, Zhang DD. Brusatol enhances the efficacy of chemotherapy by inhibiting the Nrf2-mediated defense mechanism. Proc Natl Acad Sci USA. 2011; 108:1433-38. https://doi. org/10.1073/pnas.1014275108. [PubMed]

26. Olayanju A, Copple IM, Bryan HK, Edge GT, Sison RL, Wong MW, Lai ZQ, Lin ZX, Dunn K, Sanderson $\mathrm{CM}$, Alghanem AF, Cross MJ, Ellis EC, et al. Brusatol provokes a rapid and transient inhibition of Nrf2 signaling and sensitizes mammalian cells to chemical toxicityimplications for therapeutic targeting of Nrf2. Free Radic Biol Med. 2015; 78:202-12. https://doi.org/10.1016/j. freeradbiomed.2014.11.003. [PubMed]

27. Garufi A, D’Orazi G. High glucose dephosphorylates serine 46 and inhibits p53 apoptotic activity. J Exp Clin Cancer Res. 2014; 33:79. https://doi.org/10.1186/s13046-014-00794. [PubMed]

28. Baldari S, Garufi A, Granato M, Cuomo L, Pistritto G, Cirone M, D’Orazi G. Hyperglycemia triggers HIPK2 protein degradation. Oncotarget. 2017; 8:1190-203. https:// doi.org/10.18632/oncotarget.13595. [PubMed] 
29. Garufi A, Pistritto G, Baldari S, Toietta G, Cirone M, D'Orazi G. p53-Dependent PUMA to DRAM antagonistic interplay as a key molecular switch in cell-fate decision in normal/high glucose conditions. J Exp Clin Cancer Res. 2017; 36:126. https://doi.org/10.1186/s13046-017-0596-Z. [PubMed]

30. Garufi A, Trisciuoglio D, Cirone M, D'Orazi G. ZnCl2 sustains the adriamycin-induced cell death inhibited by high glucose. Cell Death Dis. 2016; 7:e2280. https://doi. org/10.1038/cddis.2016.178. [PubMed]

31. Tacar O, Sriamornsak P, Dass CR. Doxorubicin: an update on anticancer molecular action, toxicity and novel drug delivery systems. J Pharm Pharmacol. 2013; 65:157-70. https://doi. org/10.1111/j.2042-7158.2012.01567.x. [PubMed]

32. Podhorecka M, Skladanowski A, Bozko P. H2AX phosphorylation: its role in DNA damage response and cancer therapy. J Nucl Acids. 2010; 2010. https://doi. org/10.4061/2010/920161. [PubMed]

33. Fenech M. Cytokinesis-block micronucleus cytome assay. Nat Protoc. 2007; 2:1084-104. https://doi.org/10.1038/ nprot.2007.77. [PubMed]

34. Terradas M, Martín M, Genescà A. Impaired nuclear functions in micronuclei results in genome instability and chromothripsis. Arch Toxicol. 2016; 90:2657-67. https:// doi.org/10.1007/s00204-016-1818-4. [PubMed]

35. Duan W, Shen X, Lei J, Xu Q, Yu Y, Li R, Wu E, Ma Q. Hyperglycemia, a neglected factor during cancer progression. BioMed Res Int. 2014; 2014:461917. https:// doi.org/10.1155/2014/461917. [PubMed]

36. Ryu TY, Park J, Scherer PE. Hyperglycemia as a risk factor for cancer progression. Diabetes Metab J. 2014; 38:330-36. https://doi.org/10.4093/dmj.2014.38.5.330. [PubMed]

37. Meyerhardt JA, Sato K, Niedzwiecki D, Ye C, Saltz LB, Mayer RJ, Mowat RB, Whittom R, Hantel A, Benson A, Wigler DS, Venook A, Fuchs CS. Dietary glycemic load and cancer recurrence and survival in patients with stage III colon cancer: findings from CALGB 89803. J Natl Cancer Inst. 2012; 104:1702-11. https://doi.org/10.1093/jnci/djs399. [PubMed]

38. Vishvakarma NK, Kumar A, Singh V, Singh SM. Hyperglycemia of tumor microenvironment modulates stage-dependent tumor progression and multidrug resistance: implication of cell survival regulatory molecules and altered glucose transport. Mol Carcinog. 2013; 52:93245. https://doi.org/10.1002/mc.21922. [PubMed]

39. Biernacka KM, Uzoh CC, Zeng L, Persad RA, Bahl A, Gillatt D, Perks CM, Holly JM. Hyperglycaemia-induced chemoresistance of prostate cancer cells due to IGFBP2. Endocr Relat Cancer. 2013; 20:741-51. https://doi. org/10.1530/ERC-13-0077. [PubMed]

40. Ma YS, Yang IP, Tsai HL, Huang CW, Juo SH, Wang JY. High glucose modulates antiproliferative effect and cytotoxicity of 5-fluorouracil in human colon cancer cells. DNA Cell Biol. 2014; 33:64-72. https://doi.org/10.1089/ dna.2013.2161. [PubMed]
41. Zeng L, Biernacka KM, Holly JM, Jarrett C, Morrison AA, Morgan A, Winters ZE, Foulstone EJ, Shield JP, Perks CM. Hyperglycaemia confers resistance to chemotherapy on breast cancer cells: the role of fatty acid synthase. Endocr Relat Cancer. 2010; 17:539-51. https://doi.org/10.1677/ ERC-09-0221. [PubMed]

42. Shao Y, Ling CC, Liu XQ. High concentrations of glucose suppress etoposide-induced cell death of B-cell lymphoma through BCL-6. Biochem Biophys Res Commun. 2014; 450:227-33. https://doi.org/10.1016/j.bbrc.2014.05.096. [PubMed]

43. Bergandi L, Mungo E, Morone R, Bosco O, Rolando B, Doublier S. Hyperglycemia promotes chemoresistance through the reduction of the mitochondrial DNA damage, the $\mathrm{Bax} / \mathrm{Bcl}-2$ and $\mathrm{Bax} / \mathrm{Bcl}-\mathrm{XL}$ ratio, and the cells in Sub-G1 phase due to antitumoral drugs induced-cytotoxicity in human colon adenocarcinoma cells. Front Pharmacol. 2018; 9:866. https://doi.org/10.3389/fphar.2018.00866. [PubMed]

44. Gerards MC, van der Velden DL, Baars JW, Brandjes DP, Hoekstra JB, Vriesendorp TM, Gerdes VE. Impact of hyperglycemia on the efficacy of chemotherapy-A systematic review of preclinical studies. Crit Rev Oncol Hematol. 2017; 113:235-41. https://doi.org/10.1016/j. critrevonc.2017.03.007. [PubMed]

45. Wang XJ, Sun Z, Villeneuve NF, Zhang S, Zhao F, Li Y, Chen W, Yi X, Zheng W, Wondrak GT, Wong PK, Zhang DD. Nrf2 enhances resistance of cancer cells to chemotherapeutic drugs, the dark side of Nrf2. Carcinogenesis. 2008; 29:1235-43. https://doi.org/10.1093/ carcin/bgn095. [PubMed]

46. Zhang DD. The Nrf2-Keap1-ARE signaling pathway: the regulation and dual function of Nrf2 in cancer. Antioxid Redox Signal. 2010; 13:1623-26. https://doi.org/10.1089/ ars.2010.3301. [PubMed]

47. Taguchi K, Motohashi H, Yamamoto M. Molecular mechanisms of the Keap1-Nrf2 pathway in stress response and cancer evolution. Genes Cells. 2011; 16:123-40. https:// doi.org/10.1111/j.1365-2443.2010.01473.x. [PubMed]

48. Xiang Y, Ye W, Huang C, Yu D, Chen H, Deng T, Zhang F, Lou B, Zhang J, Shi K, Chen B, Zhou M. Brusatol enhances the chemotherapy efficacy of gemcitabine in pancreatic cancer via the Nrf2 signalling pathway. Oxid Med Cell Long. 2018; 2018:2360427. https://doi. org/10.1155/2018/2360427. [PubMed]

49. Sun X, Wang Q, Wang Y, Du L, Xu C, Liu Q. Brusatol enhances the radiosensitivity of A549 cells by promoting ROS production and enhancing DNA damage. Int J Mol Sci. 2016; 17:997. https://doi.org/10.3390/ijms17070997. [PubMed]

50. Xiang Y, Ye W, Huang C, Lou B, Zhang J, Yu D, Huang $\mathrm{X}$, Chen B, Zhou M. Brusatol inhibits growth and induces apoptosis in pancreatic cancer cells via JNK/p38 MAPK/ NF- $\kappa b / S t a t 3 / B c l-2$ signaling pathway. Biochem Biophys Res Commun. 2017; 487:820-26. https://doi.org/10.1016/j. bbrc.2017.04.133. [PubMed] 
51. Golubnitschaja O, Polivka J Jr, Yeghiazaryan K, Berliner L. Liquid biopsy and multiparametric analysis in management of liver malignancies: new concepts of the patient stratification and prognostic approach. EPMA J. 2018; 9:271-85. https://doi.org/10.1007/s13167-018-0146-6. [PubMed]

52. Fröhlich H, Patjoshi S, Yeghiazaryan K, Kehrer C, Kuhn W, Golubnitschaja O. Premenopausal breast cancer: potential clinical utility of a multi-omics based machine learning approach for patient stratification. EPMA J. 2018; 9:17586. https://doi.org/10.1007/s13167-018-0131-0. [PubMed]

53. Gasparello J, Allegretti M, Tremante E, Fabbri E, Amoreo CA, Romania P, Melucci E, Messana K, Borgatti M, Giacomini P, Gambari R, Finotti A. Liquid biopsy in mice bearing colorectal carcinoma xenografts: gateways regulating the levels of circulating tumor DNA (ctDNA) and miRNA (ctmiRNA). J Exp Clin Cancer Res. 2018; 37:124. https://doi.org/10.1186/s13046-018-0788-1. [PubMed]
54. Puca R, Nardinocchi L, Starace G, Rechavi G, Sacchi A, Givol D, D’Orazi G. Nox1 is involved in p53 deacetylation and suppression of its transcriptional activity and apoptosis. Free Radic Biol Med. 2010; 48:1338-46. https://doi. org/10.1016/i.freeradbiomed.2010.02.015. [PubMed]

55. Garufi A, Ricci A, Trisciuoglio D, Iorio E, Carpinelli G, Pistritto G, Cirone M, D’Orazi G. Glucose restriction induces cell death in parental but not in homeodomaininteracting protein kinase 2-depleted RKO colon cancer cells: molecular mechanisms and implications for tumor therapy. Cell Death Dis. 2013; 4:e639. https://doi. org/10.1038/cddis.2013.163. [PubMed]

56. Traversi G, Fiore M, Leone S, Basso E, Di Muzio E, Polticelli F, Degrassi F, Cozzi R. Resveratrol and its methoxy-derivatives as modulators of DNA damage induced by ionising radiation. Mutagenesis. 2016; 31:43341. https://doi.org/10.1093/mutage/gew002. [PubMed] 